\title{
A Conceptual Model and Evaluating Experiments for Studying the Effect of Soil Deformation on Its Permeability
}

\author{
Masoud Enayat $\left(\mathbb{D}\right.$, Gholamreza Shoaei $\mathbb{D}^{D}$, and Mohammad Reza Nikudel $\mathbb{C}^{\circ}$ \\ Engineering Geology Group, Tarbiat Modares University, Tehran, Iran \\ Correspondence should be addressed to Gholamreza Shoaei; shoaei@modares.ac.ir
}

Received 19 November 2020; Revised 18 December 2020; Accepted 30 December 2020; Published 12 January 2021

Academic Editor: Angelo Marcelo Tusset

Copyright (c) 2021 Masoud Enayat et al. This is an open access article distributed under the Creative Commons Attribution License, which permits unrestricted use, distribution, and reproduction in any medium, provided the original work is properly cited.

\begin{abstract}
Soil structure and void ratio are the major factors that control the permeability changes during soil deformation. In this research, we proposed and tested a conceptual model considering these two factors based on the concept of permeability anisotropy. This model, which is expressed as $k(e)$ graph, determines the total $k$ values that soil can achieve and shows that as deformation proceeds, soil permeability passes through a specific zone in the $k(e)$ graph. Thus, by deforming a soil sample, measuring its permeability during deformation, and comparing the results using the $k(e)$ graph, it might be possible to predict deformation effects on the permeability. To evaluate this conceptual model, we designed and built a special apparatus to carry out two sets of experiments. The first set was performed to achieve the $k(e)$ graph during static compression based on the conceptual model; and the second set was conducted to investigate the permeability changes relative to $k(e)$ graph during simple shear deformation in constant volume condition. Our results show that the theoretical $k(e)$ graph agrees more with the measured $k(e)$ graph in medium to dense samples that might have no macropore. In addition, particles' preferential orientation and/or anisotropic permeability were not changed during shear deformation due to three possible causes: deformation done in constant volume deformation, relatively low shear strain, and shearing along particle orientation. Void ratio and particle orientation are associated with each other, and soil shearing with constant void ratio might cause the anisotropy of permeability to be relatively constant. Thus, it is needed to design and build a new complex apparatus or use a special method for testing how permeability changes within the $k(e)$ graph zone during soil deformation.
\end{abstract}

\section{Introduction}

When a soil body deforms, its permeability might change. Settlement, compression, consolidation, and shearing are the common causes of deformations in soils. However, less extensive deformations such as bending, torsion, and other complicated forms may also occur. Although in some of these deformations, permeability changes are negligible; they would play a key role when fluid infiltration and seepage is a matter of concern. Thus, having a good knowledge of deformation effects could be a great assistance in realistic judgment about permeability variation for designing or foresight events.

In unsaturated conditions, when soil deforms due to changes in void ratio, the degree of saturation varies leading to consequent changes in its permeability [1-3]. Green et al.
[4] reviewed the effects of various types of soil deformation on hydraulic conductivity in order to study the agricultural management practices such as tillage and reconsolidation and wheel-track soil compaction. Yeo et al. [5], Berilgen et al. [6], Fan et al. [7], and Royal et al. [8] conducted some experiments to investigate the permeability changes of slurry materials due to loading or compression occurred in the cutoff walls, cut-off barriers, and storing contaminant soils. Bryant et al. [9] investigated the permeability changes due to the consolidation of fine-grained marine sediments in various depths and introduced empirical relations to estimate the permeability from the void ratio. Morrow et al. [10], Arch and Maltman [11], Zhang and Cox [12], Crawford et al. [13], and Kimura et al. [14, 15] investigated the effect of shearing on the permeability in order to find out permeability behavior of faults and gouge materials. 
The review of previous works shows that researchers often have tried to investigate the effect of one specific deformation on the permeability, and generally, there is no comprehensive study on deformation effects. Most researchers had studied the effect of soil compression or consolidation on the permeability through studying void ratio changes on the hydraulic conductivity. This group of researchers often studied one-dimensional compression type of deformation by using the oedometer apparatus or similar devices that have rigid wall cells [5-9, 16-26]. In addition, some researchers studied axial compression with lateral free walls using either a triaxial compression device or compression cell with flexible walls [1, 3, 27-29]. Another type of study focuses on soil permeability changes during exerted shear strain. The main methods employed in this regard are ring shear $[14,18,30]$, rotary shear [31], and shear of a thin layer sample $[10,12,13,32]$.

This study is an attempt to investigate the effect of any deformation on the permeability. In this way, we described the anisotropic permeability changes during soil static compression as a conceptual model that could help to understand how any soil deformation affects the permeability. The validity of the conceptual model was investigated through sets of laboratory tests by applying an apparatus designed specifically for this research.

\section{Research Theory}

2.1. Parameters Controlling the $k$ during Soil Deformation. Soil permeability is controlled by several parameters such as grain size, specific surface area, clay content, porosity, temperature, and pore geometry [33-44]. When a soil deforms, considering laboratory constant conditions, among these effective parameters, the only varying parameters are void ratio and soil structure (including particle arrangement, orientation, and pore geometry). In this view, soil deformations can be divided into two general groups. The first group involves deformations that occur with the changing volume and both void ratio and soil structure vary. Another group comprises deformations developed with fixed volume suggesting that the void ratio is constant and only soil structure varies. Accordingly, by knowing the influence of void ratio variations and soil structure changes on the soil permeability, we can investigate the effect of soil deformation on the permeability.

\subsection{Effect of Void Ratio and Soil Structure on the $k$. Void ratio} plays a major role in permeability such that a decrease in this parameter causes a rapid declination in permeability values. Many researchers have studied the effect of void ratio variation on the permeability and some of them proposed empirical relationships to estimate permeability via void ratio [22, 42, 45-49].

In order to understand the effect of soil structure changes on the permeability during deformation, the soil should be studied in constant volume deformation condition so that the effect of void ratio could be negligible. At a certain void ratio, permeability in a specific direction could have different values depending on soil structure. In other words, in a specific void ratio, the value of $k$ depends on soil particles orientation. In a soil body, if particles have random orientation, the soil would be structurally isotropic and value of permeability in all directions is equal. However, in the same void ratio, when particles are oriented, the soil would be structurally anisotropic, leading to different permeability values in different directions. In this case, permeability in the direction parallel to soil particles orientation is more than that in the direction perpendicular to them. For these conditions, a researcher reported permeability or hydraulic anisotropy in soil, represented by the anisotropy ratio $\left(r_{k}\right)$ $[11,16-18,20,21,31,32,50,51]$, which is the ratio of horizontal to vertical permeability $\left(k_{h} / k_{v}\right)$ or ratio of larger to smaller permeability value as follows:

$$
r_{k}=\frac{k_{h}}{k_{v}}
$$

2.3. $k_{h(\max )}$ and $k_{v \text { (min) }}$ Concept. For a given soil with the specific void ratio, if the preferential orientation is at the maximum level, the horizontal permeability $\left(k_{h}\right)$ would be the maximum at this void ratio $\left(k_{h}=k_{h(\max )}\right)$ while the vertical permeability $\left(k_{v}\right)$ would be the minimum $\left(k_{v}=k_{v(\min )}\right)$. In this situation, the anisotropy ratio is at the maximum state possible $\left(r_{k(\max )}\right)$ and permeability values in other directions would be between $k_{h(\max )}$ and $k_{v(\min )}$.

2.4. The Conceptual Model. Basak [52], Delage and Lefebvre [53], Al-Tabbaa and Wood [16], Chapuis et al. [54], Brown and Moore [32], and Cetin [55] showed that low compression soils have less anisotropic structures and increasing compression causes the development of the anisotropic structure in the soil. Sloane and Kell [56] and Chapuis and Gill [17] reported that static compression creates a more anisotropic structure in fine-grained and sandy soils than dynamic or other compression methods. As a result, when a saturated soil sample with a high void ratio is one-dimensionally compressed gradually, soil particles can be displaced and rotated perpendicular to the applying load axis. Since particle rotation and structural anisotropy development continues from the beginning of soil compression, the $r_{k}$ is expected to be maximum at each void ratio. Thus, it is acceptable that the measured $k_{h}$ and $k_{v}$ at each void ratio during compression are the $k_{h(\max )}$ and $k_{v(\min )}$. Plotting the obtained $k_{h(\max )}$ and $k_{v(\min )}$ in different void ratios during one-dimensionally static compression in a log-linear scale of $k(e)$ graph would give two $k_{h(\max )}$ and $k_{v(\min )}$ curves, respectively (Figure 1). Although, the soil may be isotropic $\left(r_{k} \approx 1\right)$ at the beginning of compression, with a decrease in void ratio and increase in structural anisotropy, differences of these two curves increase, leading to the increase in anisotropic permeability (i.e. $r_{k}>1$ ). A similar behavior can be seen in the results reported by Basak [52], Wilkinson and Shipley [25], and Al-Tabbaa and Wood [16].

The $k(e)$ graph shown in Figure 1 represents a conceptual model according to which the soils composed of particles with unequal dimensions, produce anisotropic permeability 


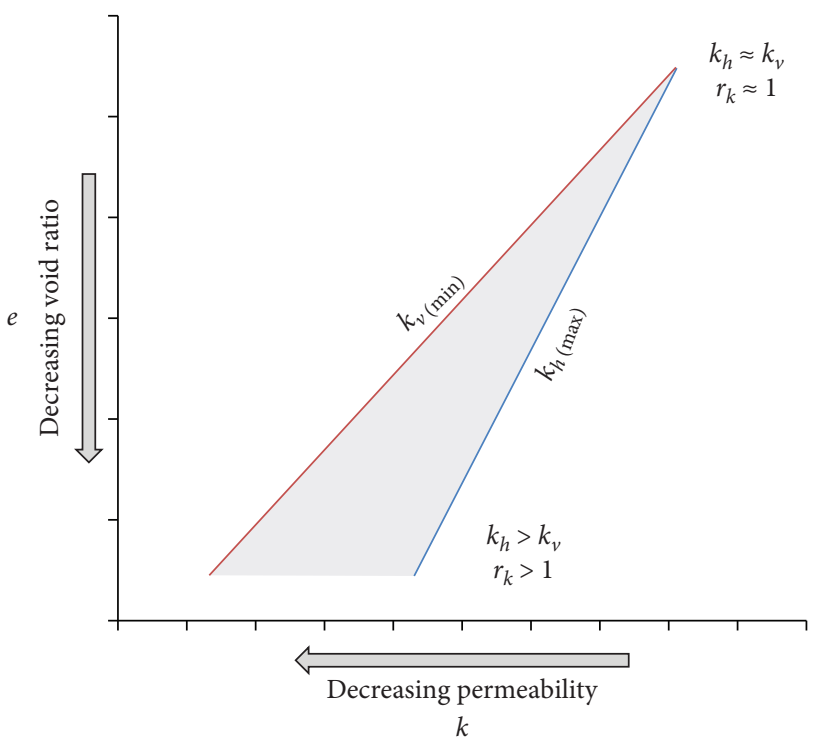

FIGURE 1: The $k(e)$ graph showing a conceptual model of $k_{h(\max )}$ and $k_{v(\min )}$ variations and anisotropic permeability development for a given soil sample having a high void ratio during static onedimensional compression.

during static compression. This model is valid until there is no fracture or canal in the soil. The $k(e)$ graph is unique for each soil sample because particle shape and geometry in different soils vary and lead to different structural anisotropies. The inferable point from the $k(e)$ graph (Figure 1) is that there is a range of $k$ value for each void ratio, where $k$ varies between $k_{h(\max )}$ and $k_{v(\min )}$ depends on the soil structure as follows:

$$
k_{h(\max )} \geq k \geq k_{v(\min )} .
$$

In fact, when a soil body with having $k_{h(\max )}$ and $k_{v(\min )}$ (i.e., $\left.r_{k(\max )}\right)$ deformed, it is expected to cause the soil structure changed; consequently, anisotropy structure decreased from the initial state caused $k$ varied between $k_{h(\max )}$ and $k_{v(\min )}$. Therefore, when a soil body deforms with a constant volume, it is expected that $k$ varies only between $k_{h(\max )}$ and $k_{v(\min )}$ values; however, when it deforms with a changing volume, it is needed to estimate the $k$ in relation to its corresponding void ratio. The dashed area between the two curves in Figure 1 presents all possible values of $k$ that soil can achieve under normal conditions. As can be seen, $k$ is not located out of this region except in special conditions, e.g., when soil grading or particle shape changes due to some process like grain crash as a result of excessive loading or water movement along produced fractures.

Thus, any deformation that could occur in the soil, in either a constant or a changing volume, would lead to changes in the permeability within the dashed area in Figure 1. Accordingly, the pattern of $k_{h}$ and $k_{v}$ variation during soil deformation with respect to $k_{h(\max )}$ and $k_{v(\min )}$ curves in the $k(e)$ graph can show the effect of soil deformation on its permeability.

Although, the conceptual model maybe theoretically valid for all soil types, in practice, it may not work properly for cohesionless granular soils, because particles in these soils cannot rotate freely under static compression. After a slight compression, they interlock and resist against volumetric compaction [57]. This behavior prevents the development of anisotropic structures in these soil types.

\section{Methodology and the Procedure}

We tried to study the permeability changes during soil deformation via laboratory tests based on the conceptual model (Figure 1). For this purpose, a procedure with the following steps was defined as follows:

(1) Preparing the $k(e)$ graph $\left(k_{h(\max )}\right.$ and $k_{v(\min )}$ curves $)$ of soil samples

(2) Determining the $k_{h}$ and $k_{v}$ variations of soil samples during progressive simple shear deformation

(3) Comparison of obtained results from steps 1 and 2 in order to determine how the soil permeability changed during deformation within $k(e)$ graph zone

Step 1 includes experiments conducted to obtain $k_{h(\max )}$ and $k_{v(\min )}$ values in different void ratios during one-dimensional static compression in order to prepare the $k(e)$ graph.

In step 2, tests were carried out to measure $k_{h}$ and $k_{v}$ variations during simple shear deformation. Through this deformation type, it is possible to deform the soil sample without changing its volume. As a result, we can investigate only the effect of soil structure changes on the permeability without the effect of void ratio variation.

Finally, in step 3, the results of the second step of experiments were plotted on the $k_{h(\max )}$ and $k_{v(\min )}$ curves were obtained from the first step of experiments to display how the permeability changed with respect to its initial state during simple shear deformation. So, it can be determined that whether measured $k_{h}$ and $k_{v}$ changed between $k_{h(\max )}$ and $k_{v(\min )}$ curves according to the conceptual model or not.

The mechanism of simple shear deformation is schematically illustrated in Figure 2. In this deformation type, theoretically, material shear and deformation occur without volume change. Here, shear strain $(\gamma)$ is defined as the ratio of shear displacement $(D)$ to the height of the sample or thickness of shear $(H)$ as follows:

$$
\gamma=\frac{D}{H}
$$

3.1. Samples Specifications. To examine the conceptual model, we need a remolded homogeneous sample in order to eliminate the effect of cracks and fractures on the permeability. Thus, two fine-grained soils with no organic matter were selected from loess soil deposits which are widespread in Golestan province, Northern Iran (Table 1). Rezaee et al. [58] showed that the sphericity of the loess particles is between 0.66 and 0.8 with an average of 0.73 . 


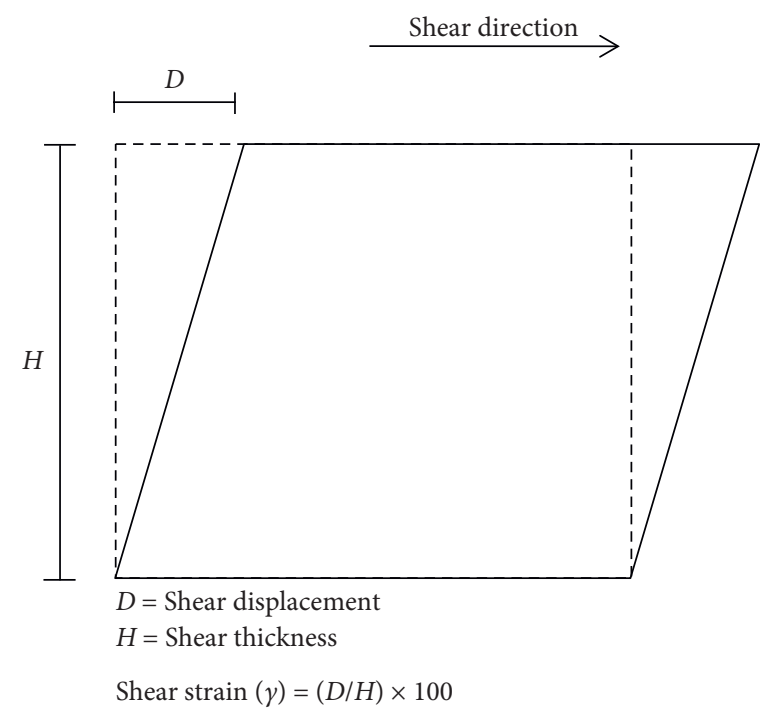

FIgURE 2: The mechanism of simple shear deformation.

TABLE 1: Specifications of the soil specimens.

\begin{tabular}{lccccccc}
\hline Sample & $\begin{array}{c}\text { Unified } \\
\text { classification }\end{array}$ & $\begin{array}{c}\text { Liquid limit (LL) } \\
(\%)\end{array}$ & $\begin{array}{c}\text { Plasticity index } \\
(\mathrm{PL})\end{array}$ & $\begin{array}{c}\text { Specific gravity }(\mathrm{Gs}) \\
\left(\mathrm{g} / \mathrm{cm}^{3}\right)\end{array}$ & $\begin{array}{c}\text { Sand } 2-0.075 \mathrm{~mm} \\
(\%)\end{array}$ & $\begin{array}{c}\text { Silt } 2-75 \mu \mathrm{m} \\
(\%)\end{array}$ & $\begin{array}{c}\text { Clay }<2 \mu \mathrm{m} \\
(\%)\end{array}$ \\
\hline I & $\mathrm{CL}$ & 30 & 11 & 2.68 & 28 & 51 & 21 \\
$\mathrm{II}$ & $\mathrm{CL}$ & 34 & 14 & 2.72 & 8 & 66 \\
\hline
\end{tabular}

3.2. Test Apparatus. In order to implement the two sets of tests (for steps $1 \& 2$ ), it was necessary to design and built a special test apparatus. This apparatus must have two main capabilities; first, it should be able to apply an incremental static force to consolidate one-dimensionally the soil sample from a high void ratio to measure $k_{h(\max )}$ and $k_{v(\min )}$ values at the end of each compression step. Second, it should be able to apply simple shear strain to the soil sample and measure the permeability at the end of each simple shear strain. The schematic of the apparatus is illustrated in Figure 3.

This apparatus can measure $k_{h}$ and $k_{v}$ values separately through both falling and constant head methods. The cell has a square cross-section with a dimension of $8 \mathrm{~cm}$ and a height of $20 \mathrm{~cm}$. Here, $k_{h}$ can be measured with two components assigned as $k_{h 1}$ and $k_{h 2}$.

The shear zone thickness in the sample during shear deformation is $5 \mathrm{~cm}$; so, the dimensions of the sample deformed during the simple shear deformation are $8 \mathrm{~cm} \times 8 \mathrm{~cm} \times 5 \mathrm{~cm}$. The cell is composed of three parts (Figure 3): the upper part is always fixed during compression or shear deformation, the lower part is fixed during the compression test. But, during shear deformation, it can move on a precision rail to the left or right with a fixed strain rate of $0.05 \mathrm{~mm} \cdot \mathrm{sec}^{-1}$. The middle part of the cell is a section at which the test sample bears shear deformation during the displacement of the lower part (Figures 3(a) and 3(b)).

Shear deformation in this paper was reported as a strain percentage such that each $1 \mathrm{~mm}$ of lateral displacement of the lower part of the cell on the rail is equal to a $2 \%$ shear strain.

3.3. Samples Preparation and Test Method. Samples with a high void ratio can be prepared by two slurry and powder methods. Since performing desired tests on the slurry sample is difficult and involves high mistakes, we decided to prepare the samples using the powder method. For this purpose, soil samples were dried and crushed and then passed through sieve no. $10(2 \mathrm{~mm})$ such that to obtain a homogeneous soil powder. The prepared powder was put in the cell using a long pipe funnel placed at a constant $2 \mathrm{~cm}$ height. Afterward, when the loading piston is located in the cell, the cap would be fitted, closed, and sealed.

Before the beginning of the test, the soil is saturated from the lower to upper openings through the cell valves (Figure 3); as a result, air exits from the upper cell valve. After saturating and deairing the sample, it is ready for the test.

Horizontal permeability in all tests measured with two components: $k_{h 1}$ and $k_{h 2}$. In permeability experiments, during shear deformation, $k_{h 1}$ is the permeability along the shear direction of the sample; thus, $k_{h 2}$ is perpendicular to the shear direction.

For the first set of tests (step 1), after each increment stage of the static load and soil compression, the sample is allowed to reach a new equilibrium condition until displacements are zero. Next, horizontal and vertical permeability values are measured separately. 


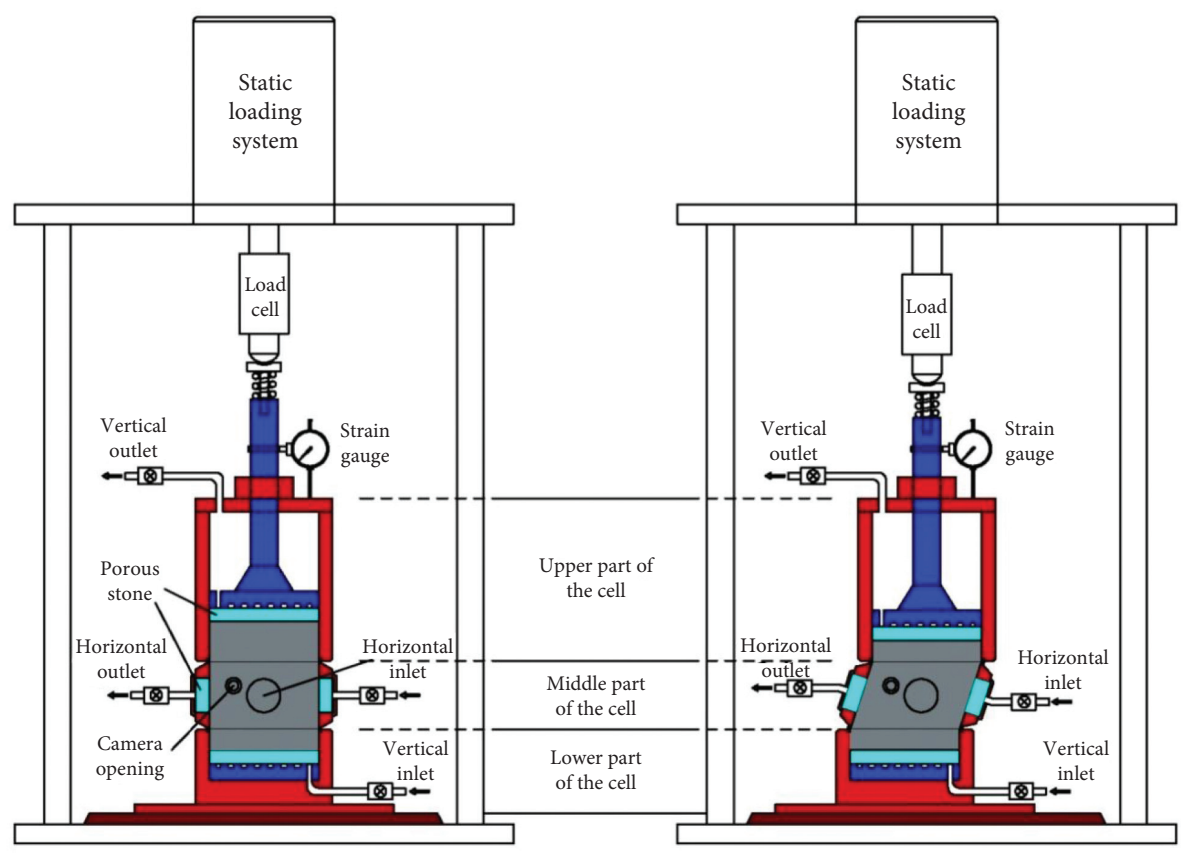

(a)

(b)

Figure 3: The layout of the test apparatus; (a) compression deformation of the soil sample and (b) simple shear deformation of the soil sample.

For the second set of tests (step 2), the sample compressed until reaching the desired void ratio. Then, to prevent the soil volume changes during the shear deformation, especially in dense samples, their vertical load was released and set to about $1 \mathrm{~kg} / \mathrm{cm}^{2}$. However, the applied load was not completely released because removing the load can cause detachment between the sample body and cell wall or produce opening fractures in the sample. After compressing the soil to the desired void ratio, setting the vertical load, and reaching an equilibrium state, the $k_{h}$ and $k_{v}$ values were measured. Then, soil sheared by $1 \mathrm{~mm}$ shear displacement of the lower part of the cell, which is equivalent to $2 \%$ shear strain. After this shearing and reaching an equilibrium state, $k_{h}$ and $k_{v}$ values were measured. This process comprises shearing, reaching an equilibrium state, and measuring $k_{h}$ and $k_{v}$ was repeated until the cell sealing is not damaged by shear displacement.

It has to be noted that all horizontal and vertical permeability were measured after water flow reached a steady state. Measurements in each step were replicated at least 5 times, and the final value was reported as their average.

\section{Results and Discussion}

4.1. First Step Results: The $k(e)$ Graph of Samples. Variations of $k_{h(\max )}$ and $k_{v(\min )}$ corresponding to the void ratio in each step of progressive compression for I and II samples (the $k(e)$ graphs) are illustrated in Figures 4 and 5, respectively.

Results show that permeability variations of samples I and II during the static compression were similar, in general. There is a linear relationship between the void ratio and the logarithm of $k_{v(\mathrm{~min})}$, similar to previously published data
$[9,16,20,26,42,59-62]$. However, the decrease in $k_{h(\max )}$ differs from $k_{v(\min )}$ and is not linear. As illustrated in Figure 6, the anisotropic permeability ratio $\left(r_{k}\right)$ of samples has a varying trend during the compression, despite what is expected from the conceptual model. Here, $r_{k}$ is expressed as $k_{h(a v)} / k_{v}$ which $k_{h(a v)}$ denotes the average of $k_{h 1}$ and $k_{h 2}$.

As presented in Figure 6, the sample's $r_{k}$ increases rapidly from the beginning of the compression and reaches a maximum level. Then, the increase in compression resulted in a rapid decrease in $r_{k}$ until reaching near a minimum level. After this drop, at medium void ratios, $r_{k}$ almost has minimum values with relatively low variations during the compression but it increases again at low void ratios.

Soil structure observations during the compression show that $r_{k}$ changes were affected by the variation in the geometry of large pores and particle orientation (Figure 7). Macrostructure of the soil was examined using the images captured by a camera installed on the cell wall (Figure 3). Because of the sample preparation method, the samples have a granular structure at the high void ratios and mostly are composed of large units such as ped grains and silt-size grains [63] as well as other fine units such as clays and clay size particles (Figures 7(a) and 7(b)). Additionally, pores with various sizes are seen in the samples; macropores distribute between large units while micropores distribute within these large and fine units $[53,63,64]$.

When the soil has a high void ratio, water flows mostly through the macropores. In this regard, permeability is controlled by these pores rather than micropores that are influenced by the capillary force $[22,65,66]$. But at low void ratios, macropores are absent and hydraulic conductivity is controlled by micropores [67]. 


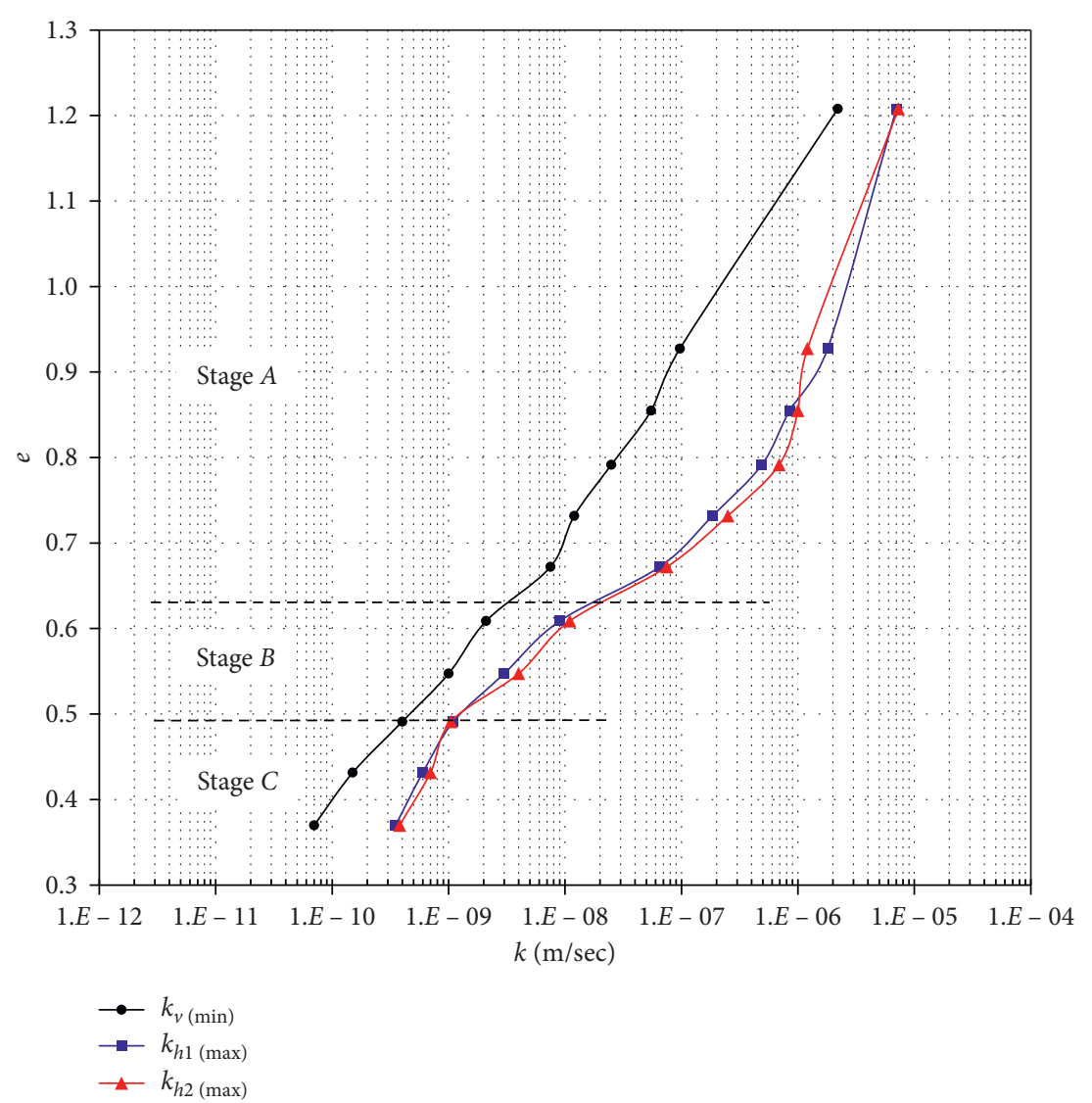

FIgURE 4: The $k(e)$ graph for sample I.

Macropores are more sensitive to compaction compared to micropores $[23,68]$. During soil compaction or consolidation, larger pores close first [53,69-73]. This evolution of soil structure affects the permeability and $r_{k}$ variations during soil static compression. Following these variations, generally, three stages can be recognized (Figures 4-6) as follows:

Stage A. A high anisotropic permeability in low compressions due to macropores effects (pseudoanisotropic permeability)

Stage $B$. The lowest amount of anisotropic permeability in medium compressions due to the elimination of macropores affects and undeveloped orientation of the soil particles

Stage C. Gradual increase of anisotropic permeability at high compressions due to developing particle orientation

In Stage $A$, the soil has a granular structure and water flow is controlled by macropores (Figure 7(b)). Anisotropic permeability comes from flattening the ped grains and interped macropores perpendicular to the applied load axis. Although fine particles are resorted within larger units (i.e., ped grains), they do not show a clear preferential orientation. Considering the importance of macropores in control of water flow and permeability, there are maximum anisotropy ratios in this stage, and therefore, there is pseudoanisotropy in this stage [63].
At the beginning of compression in this stage, $r_{k}$ is relatively low but later with a small compression, ped grains, and interped macropores started to deform, and due to the affection of interconnected interped macropores, $r_{k}$ reached a maximum level. In the following, as compression proceeded, peds started to merge and macropore flow paths were disconnected. This process caused permeability and $r_{k}$ to decline rapidly.

In $B$ stage, ped grains disappeared so there are no large pores in the soil body but few remnant macropores may exist as trapped spaces that started to complete the closure (Figure 7(c)). So decrease in the void ratio during compression in this stage is expected to occur mostly through decreasing the micropores size and particle rotation. There is the least anisotropic permeability in this stage because of the absence of macropores and the lack of evolution in particle orientation. Rotation of particles still is not enough to have a noticeable effect on the increasing $r_{k}$.

In Stage $C$, soil completely is compressed and there is no macropore in the soil body (Figure $7(d)$ ). The decreasing void ratio continues by a decrease in micropore size and particle rotation. The $r_{k}$ increases gently due to the development of particle orientation during the compression.

Soil structure evolution through these three stages indicates that, in stages $A$ and $B$, soil particles do not have a preferential orientation and it is only in $C$ stage that a preferential orientation is developed. So only in the $C$ stage, a 


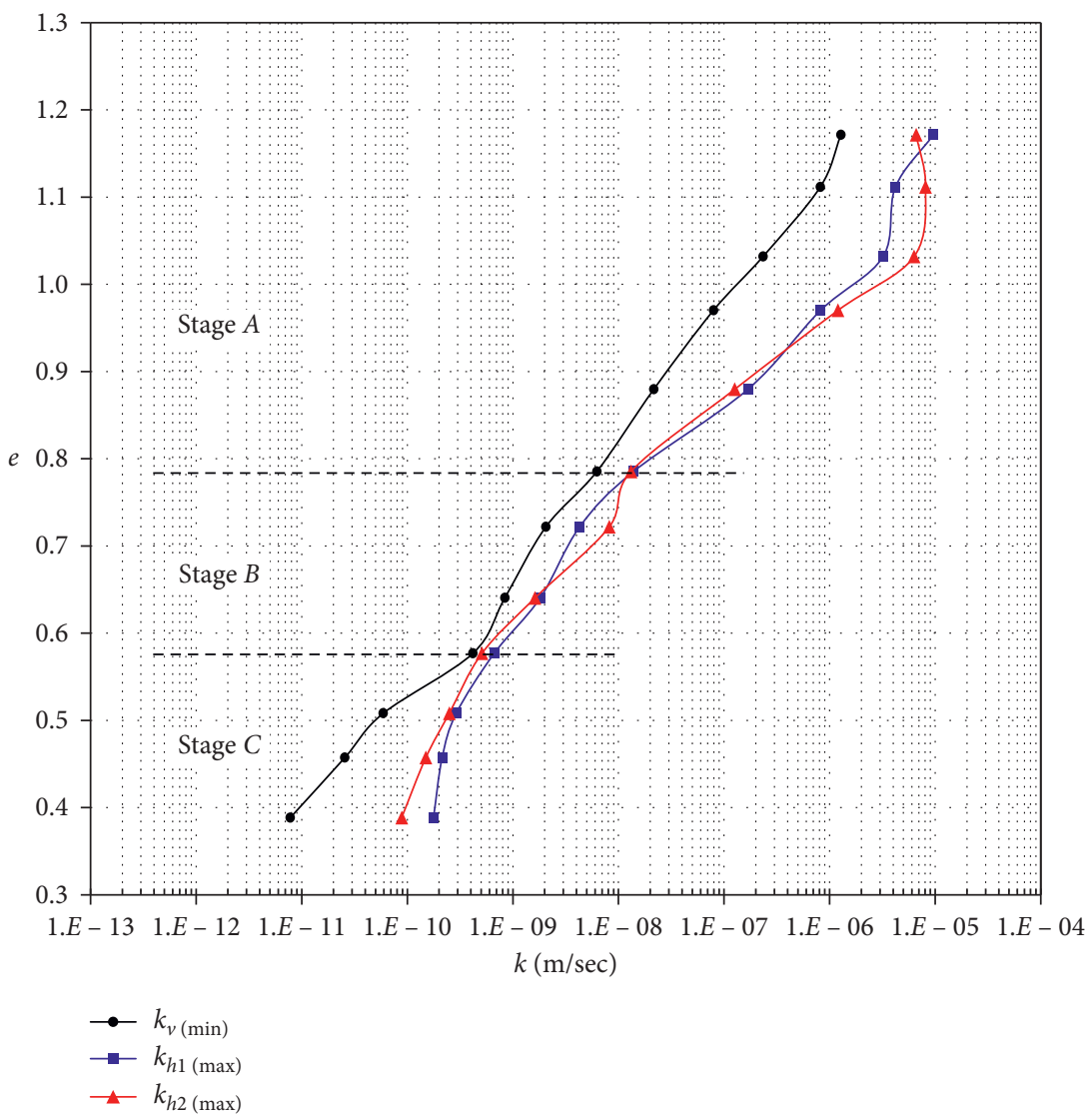

Figure 5: The $k(e)$ graph for sample II.

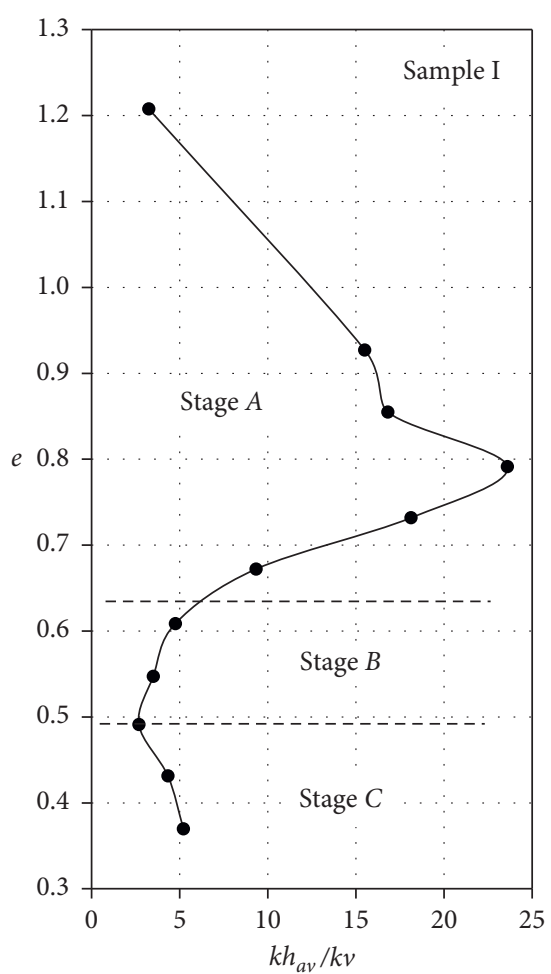

(a)

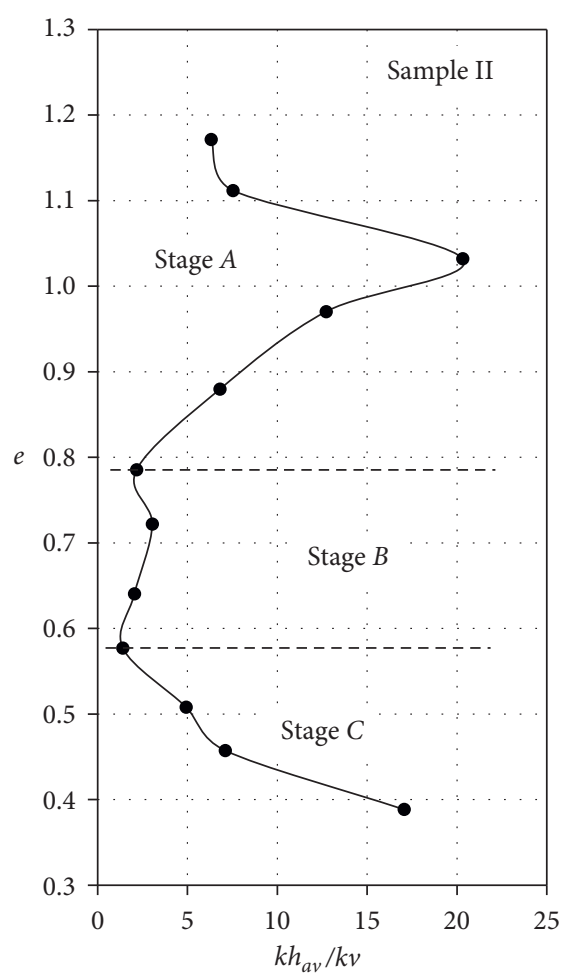

(b)

FIGURE 6: Anisotropic permeability variations of samples during the static compression. 


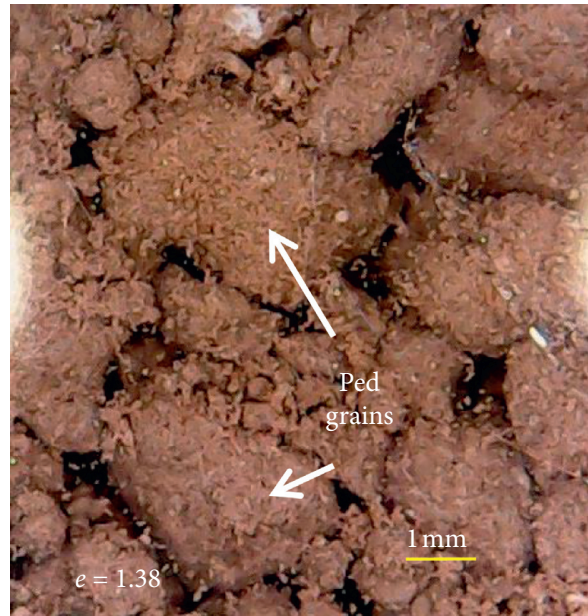

(a)

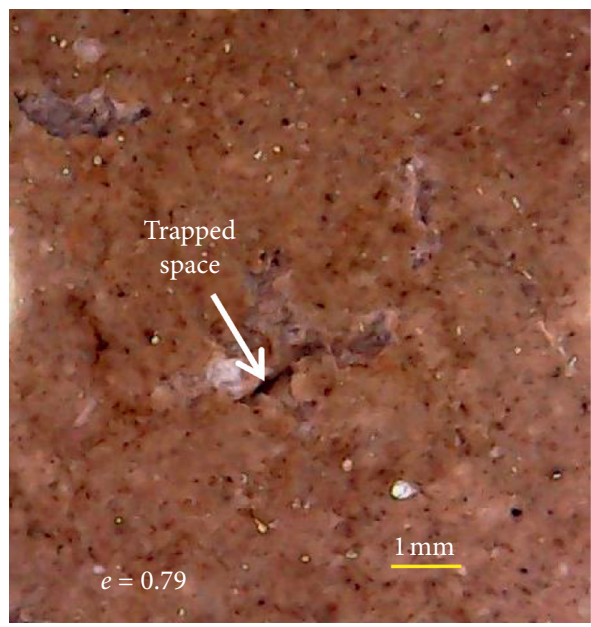

(c)

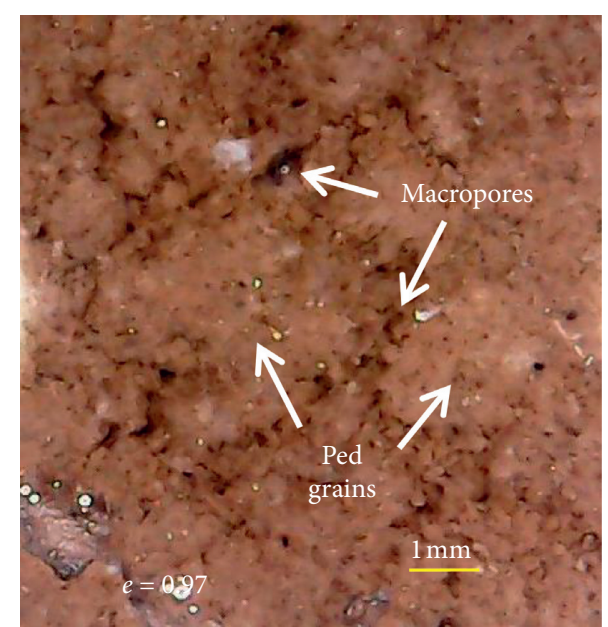

(b)

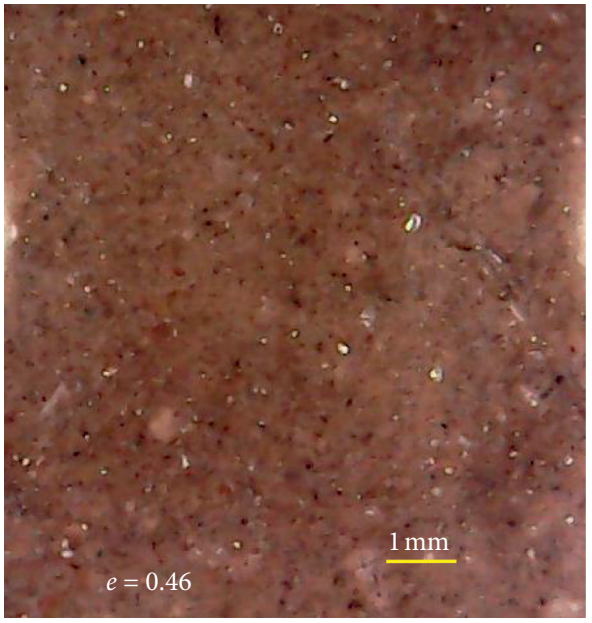

(d)

FIgURE 7: Evolution of soil structure during one-dimensionally compression of sample I.

variation of $k_{h(\max )}$ and $k_{v(\min )}$ during compression coincide with the conceptual model. This result shows that the sample preparation method affects the $k_{h(\max )}$ and $k_{v(\min )}$ curves in the $k(e)$ graph at relatively high void ratios, which are marked by $A$ and $B$ stages. Preparing the sample by the powder method, which was employed in this research, caused the creation of large pores in the soil body and prevented the development of particles preferential orientation until these pores were closed completely. This behavior coincides with the results of Yong and Warkentin [63].

4.2. Second Step Results: Variations of $k$ during Progressive Simple Shear Deformation. Experiments of the permeability changes during simple shear deformation conducted for all defined three stages $A, B$, and $C$, so that to determine variations of $k_{h}$ and $k_{v}$ related to $k_{h(\max )}$ and $k_{v(\min )}$ curves in the $k(e)$ graph.

The measured $k_{v}, k_{h 1}$, and $k_{h 2}$, after each step of $2 \%$ incrementing simple shear strain for samples I and II are presented in Figures 8 and 9, respectively. Specifications of samples at the beginning of the tests are presented in Table 2.
In stages $A$ and $B$, sealing of cell was failed at low shear strain (due to the low compression of the soil sample) thus the experiment was terminated and the strain developed in the sample did not exceed $10 \%$.

4.3. Third Step Results: Comparison of the Results from Steps 1 and 2. The measured $k$ values in step 2 (Figures 8 and 9) are plotted on the related $k(e)$ graph and shown in Figures 10 and 11. The pattern of points scattering in these figures shows that except in some cases, other plotted data generally are consistent with $k_{h(\max )}$ and $k_{v(\min )}$ curves. Examples of these contradictory behaviors are seen in data such as $k_{h 2}$ in II sample in Stage $A$ or $k_{h 1}$ and $k_{h 2}$ in sample I in Stage $A$, which are failed data or arisen due to the closure effect of large pores and conduits (summary of the comparison results are presented in Table 2).

This result is unlike the behavior expected from the conceptual model that had expressed structure changes caused permeability changed between $k_{h(\max )}$ and $k_{v(\min )}$ curves. For example, in Stage C of samples in which soil particles orientation is developed, even slight increases in 

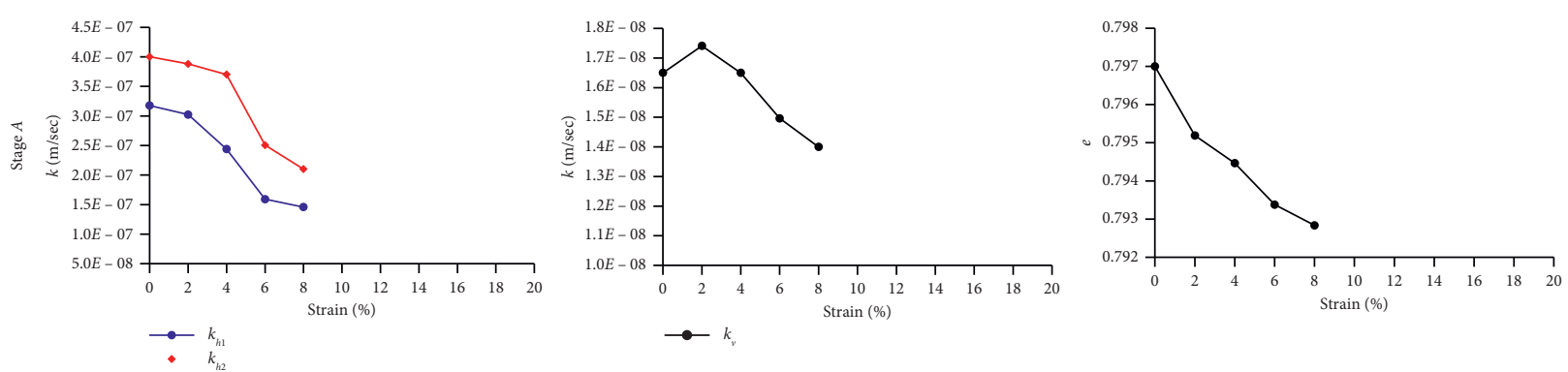

(a)
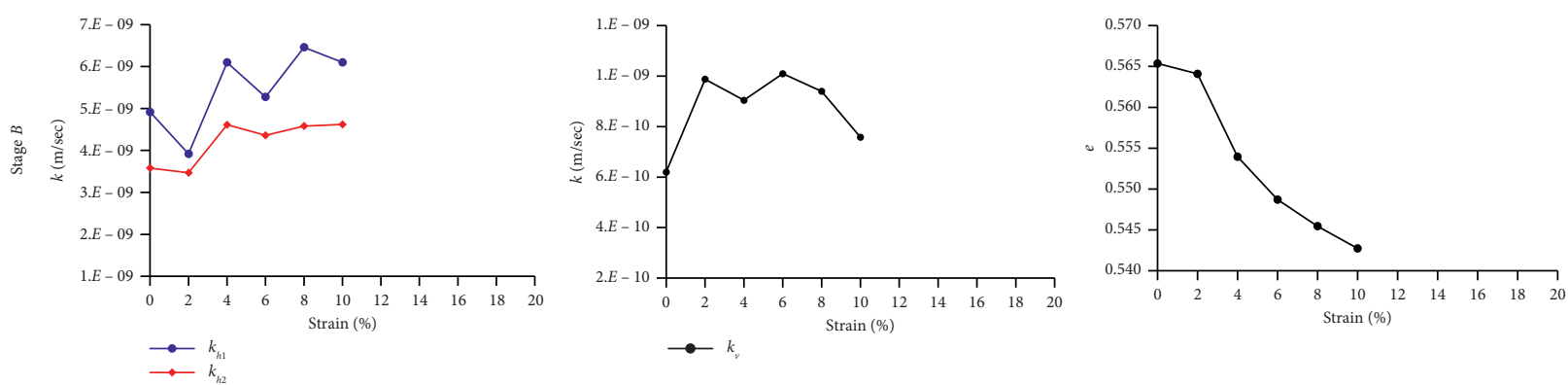

(b)
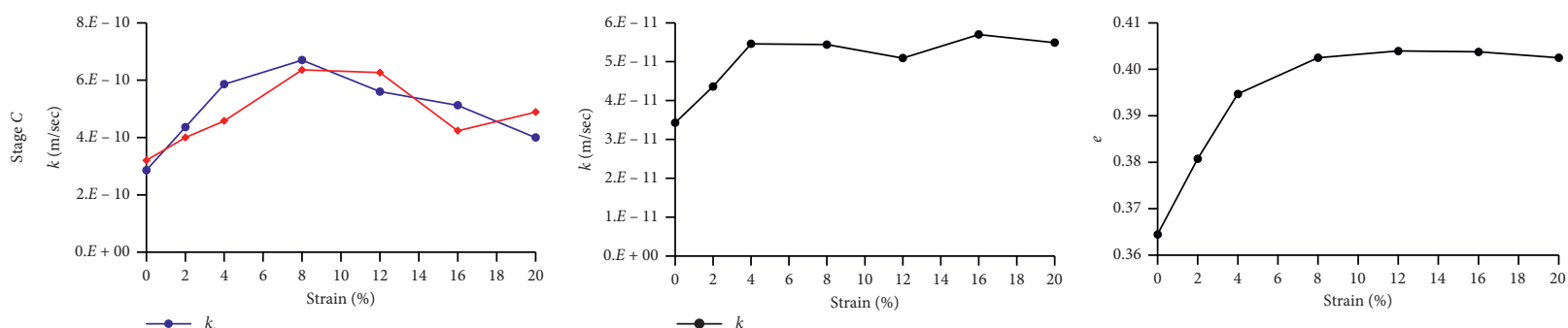

(c)

FIGURE 8: Variation graphs of $k_{h 1}, k_{h 2}, k_{v}$, and $e$ vs. strain for each stage of sample I.
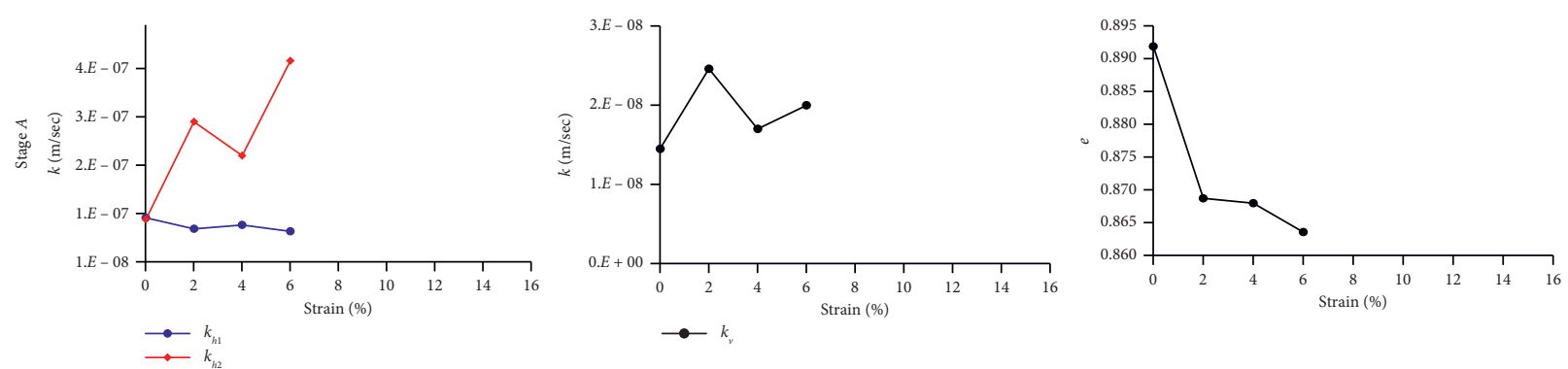

(a)
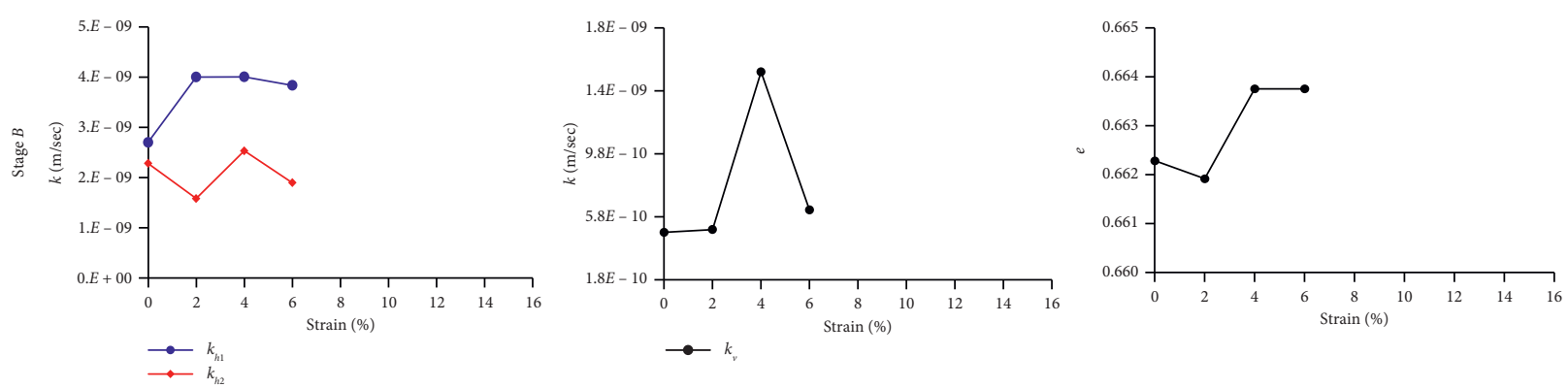

(b)

Figure 9: Continued. 


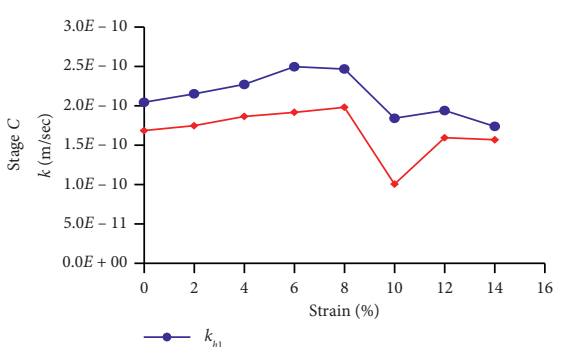
$\longrightarrow \begin{array}{ll}\longrightarrow & k_{h 1} \\ \longrightarrow & k_{h 2}\end{array}$
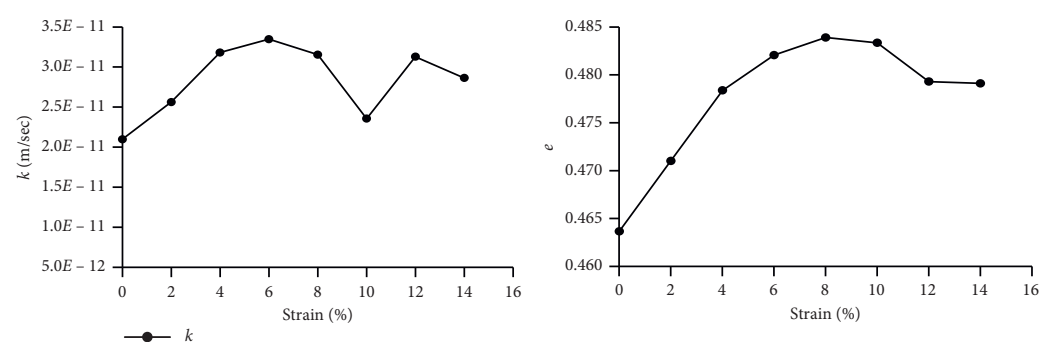

(c)

FIGURE 9: Variation graphs of $k_{h 1}, k_{h 2}, k_{v}$, and $e$ vs. strain for each stage of sample II.

TABLE 2: Specifications of samples and their permeability change behaviour during simple shear deformation tests.

\begin{tabular}{|c|c|c|c|c|c|c|c|c|}
\hline $\begin{array}{l}k_{h 2} \text { variation } \\
\text { during s. sh. def. }\end{array}$ & $\begin{array}{c}k_{h 1} \text { variation } \\
\text { during s. sh. def. }\end{array}$ & $\begin{array}{c}k_{v} \text { variation } \\
\text { during s. sh. def. }\end{array}$ & $\begin{array}{l}\text { Initial } \\
\text { vertical } \\
\text { loading } \\
\left(\mathrm{kg} / \mathrm{cm}^{2}\right)\end{array}$ & $\begin{array}{l}\text { Induced shear } \\
\text { strain }(\%)\end{array}$ & $\begin{array}{c}\text { The maximum } \\
\text { variation of }(e) \text { during } \\
\text { s. sh. def. }\end{array}$ & $\begin{array}{c}\text { Initial } \\
\text { void ratio }\end{array}$ & Stage & Samples \\
\hline- & - & + & 0.5 & 8 & 0.004 & 0.80 & $A$ & \\
\hline+ & $x$ & + & 1.6 & 10 & 0.023 & 0.57 & $B$ & I \\
\hline+ & + & + & 1.1 & 20 & $-0.039^{*}$ & 0.36 & C & \\
\hline$x$ & + & + & 0.8 & 8 & 0.028 & 0.89 & $A$ & \\
\hline+ & + & + & 1.2 & 10 & $-0.002^{*}$ & 0.66 & $B$ & II \\
\hline+ & + & + & 1.3 & 14 & $-0.02^{*}$ & 0.46 & $C$ & \\
\hline
\end{tabular}

+ Permeability changes coincide with $k_{h(\max )}$ and $k_{v(\min )}$ curves and have a similar trend. -Permeability changes are not consistent with $k_{h(\max )}$ and $k_{v(\min )}$ curves. $\times$ Inaccurate, an outlier or uncertain data. ${ }^{*}$ Negative numbers indicate the swelling and increasing void ratio during simple shear deformation.

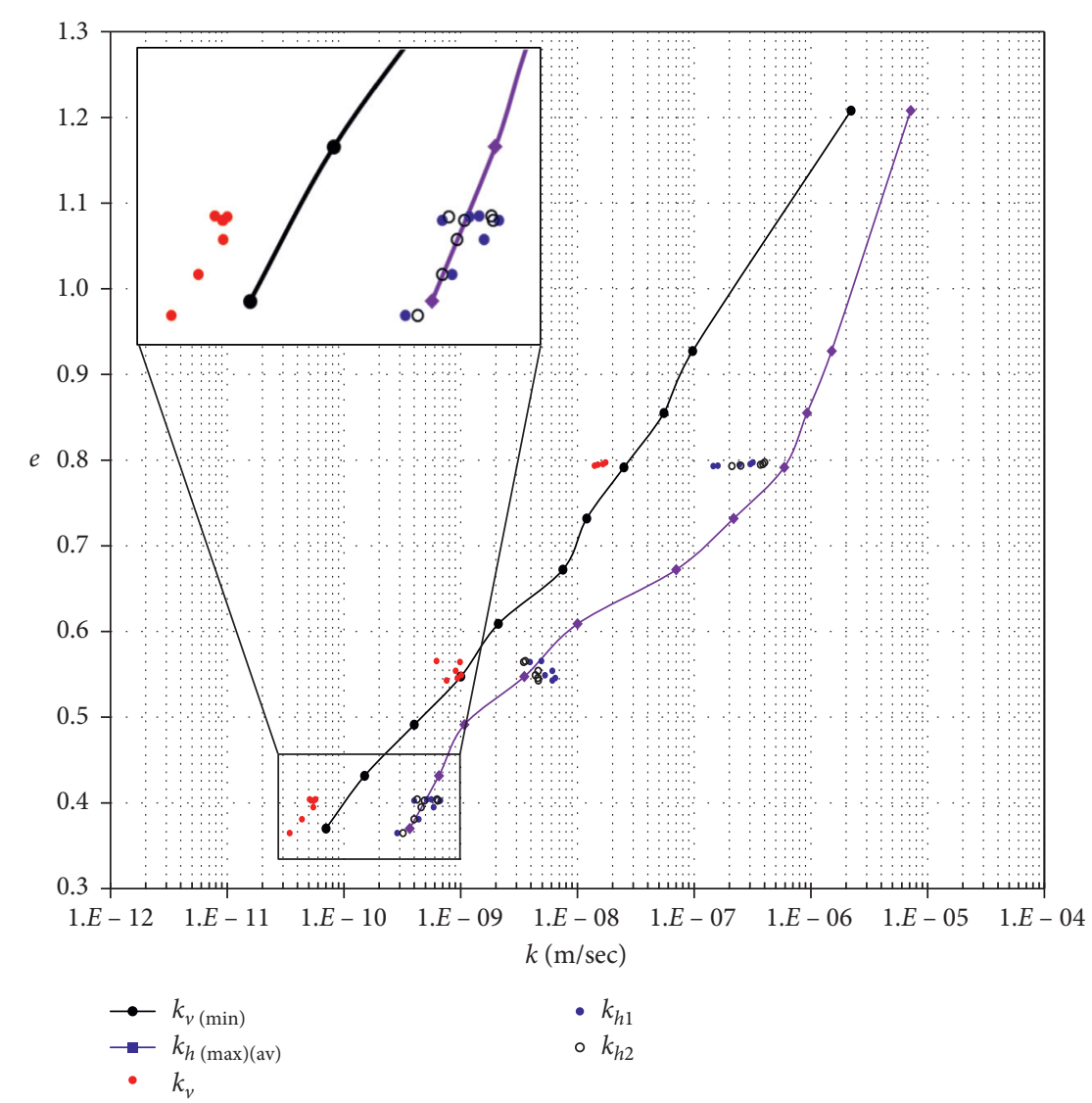

FIGURE 10: The plot of the $k_{v}, k_{h 1}$, and $k_{h 2}$ values measured during simple shear deformation on the $k_{h(\max )}$ and $k_{v(\min )}$ curves for sample I. 


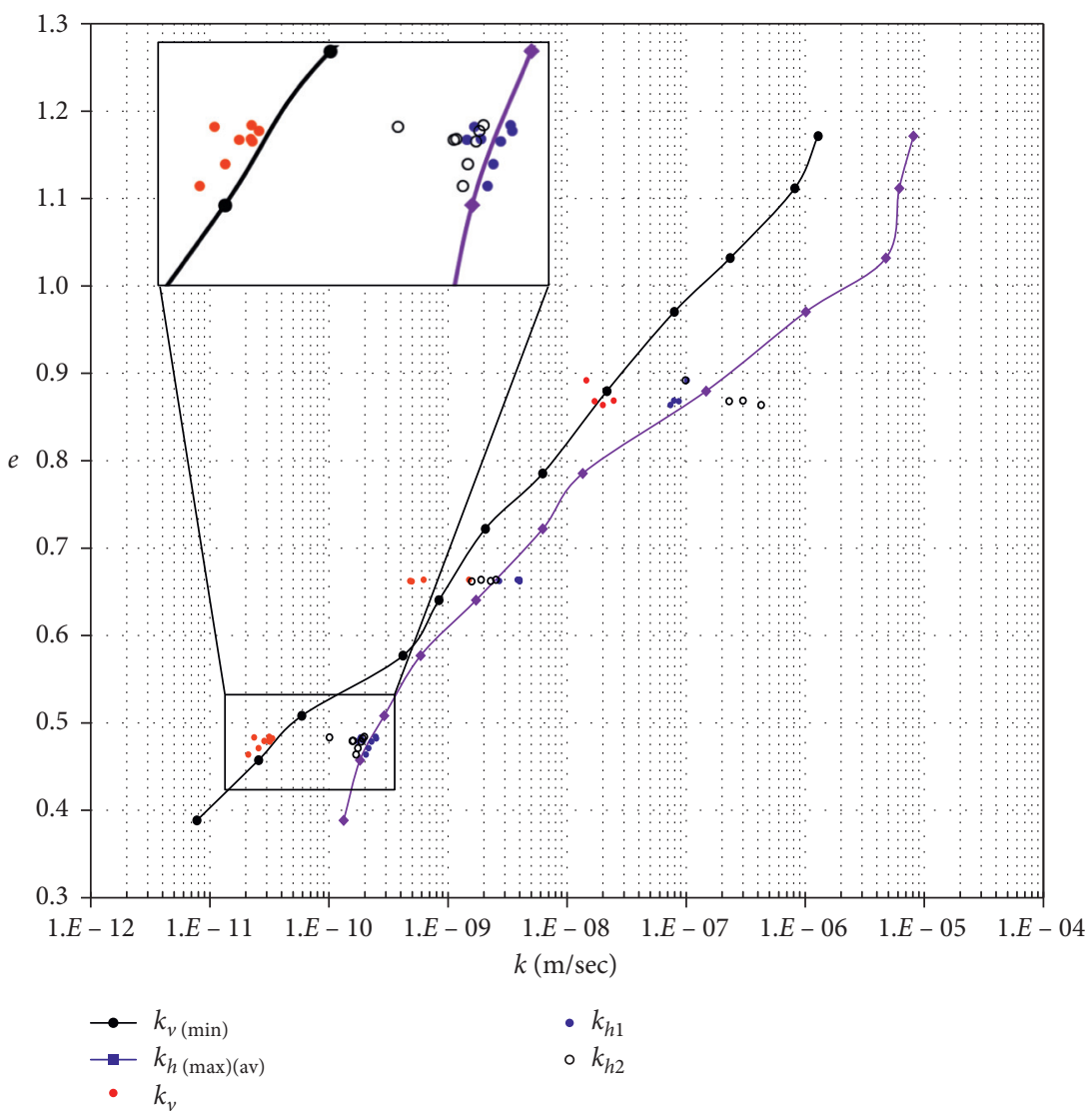

FIGURE 11: The plot of the $k_{v}, k_{h 1}$, and $k_{h 2}$ values measured during simple shear deformation on the $k_{h(\max )}$ and $k_{v(\min )}$ curves for sample II.

void ratios due to swelling caused by shearing led to a scattering data trend similar to $k_{h(\max )}$ and $k_{v(\min )}$ curves (Figures 10 and 11). This result proves that permeability mainly is affected by void ratio changes and structural changes have a negligible effect on it. This result is in line with the findings of other researchers $[32,74]$.

Lack of consistency between the second set of experiments results and conceptual model predictions arises from the fact that in constant volume condition; the induced simple shear deformation cannot produce significant changes in particle orientation. Soil macrostructure observations during shear deformation confirm this point in all shear deformation tests. Figure 12 illustrates the angularity changes of a small fragment of a gastropod shell in sample I during the static compression. These remnant shell fragments could be found in Golestan province loess deposits. It was noted that fragment angle related to the horizontal plane (perpendicular to applied load or parallel to shear direction) decreased by $23^{\circ}$ with a decrease in a void ratio from 0.95 to 0.68 .

Also, a simple shear strain was applied to this sample at a void ratio of 0.8 (stage $A$ of sample I in Table 2). The structure observed for this sample revealed that, during the shear deformation up to $8 \%$ strain, the angle of the shell did not change. Thus, it is obvious that the effect of simple shear deformation on particle orientation is negligible compared to the effect of compression; so the shear deformation under constant volume conditions cannot change the initial soil particles orientation i.e., soil structural anisotropy. For this

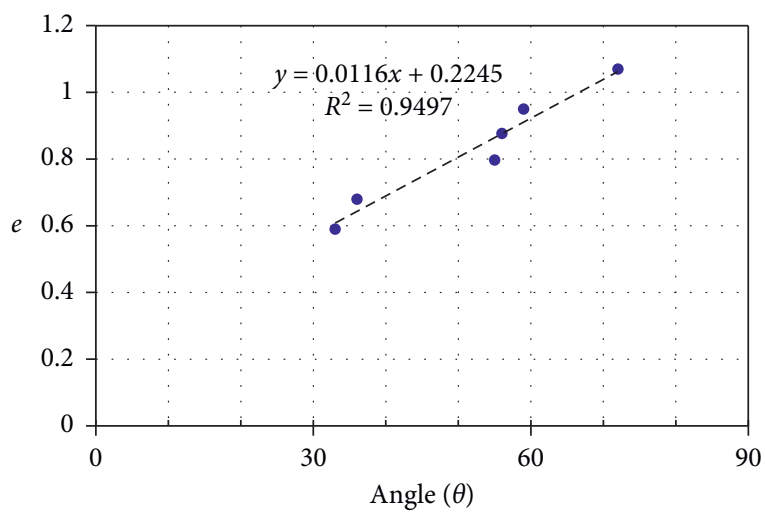

FIGURE 12: The rotation angle of a gastropod skeleton fragment from applied simple shear direction during one-dimensional static compression.

reason, permeability variations during the shear deformation have the most dependency to the void ratio. As a result, plotted data in Figures 10 and 11 are consistent with the $k_{h(\max )}$ and $k_{v(\min )}$ curves and show a similar trend. Another two effective factors might be mentioned that could cause the anisotropic permeability relatively constant during soil shear deformation. First, exerted shear strain was inadequate to develope anisotropic permeability with comparison to severe shearing in other phenomena such as fault zones and shear plane of landslides. Secondly, exerted shear strain took 
place tangential to particle orientation. This caused the particles to slide against each other with no change in their orientations or soil volume.

So, it is necessary to change the void ratio during shear deformation to rotate the soil particles and increasing anisotropic permeability. According to Arch and Maltman [11], shear deformation with the decreased void ratio produces the highest amount of orientation compared with compression or shear deformation alone. It is reported in some previous studies that the shear deformation produces much anisotropy rather than compression $[11,13,18,25,32,75]$ but according to findings of this research, it reveals that shear deformation and compression occurred simultaneously.

\section{Summary and Conclusions}

The results of the first set of experiments revealed that when the soil is statically compressed from a high to low void ratio, generally three stages of anisotropic permeability variations could be recognized on the $k(e)$ graph based on the soil structure evolution. Toward the end of stage $B$ at medium to low void ratio, the variations of $k_{h(\max )}$ and $k_{v(\min )}$, as well as $r_{k}$, has a good consistency with the conceptual model. This is most likely due to the absence of large pore spaces in the soil body as well as soil particles orientation perpendicular to the applied load. In samples with a high void ratio (both samples in stage $A$ ), the macropores play a main role in affecting the permeability, and thus, affect the $k(e)$ graph. So, for these samples, macropore properties, due to the sample preparation method, seem to have the main effect on the $k(e)$ graph. It means that the $k(e)$ graph varied with the sample preparation method for each soil type.

Results of the second set of tests show that measured $k$ values during simple shear deformation coincide with $k_{h(\max )}$ and $k_{v(\min )}$ curves, suggesting that permeability is mainly affected by void ratio and permeability anisotropy not changed significantly; so the measured $k_{h}$ and $k_{v}$ are not located within the area between $k_{h(\max )}$ and $k_{v(\min )}$ curves. It seems that the lack of changes in the anisotropic permeability arises from the three points: first, deformation was created under constant volume conditions, second, shear strain is relatively low, and third, shear strain exerted along particle orientations. Deformation in fixed volume conditions may produce few changes in the soil structure but cannot significantly change the orientation of soil particles; because the creation of particles with preferential orientation eliminates spaces and could lead to volume reduction. On the contrary, the reduction in particles' preferential orientation caused the volume increase. Therefore, the key point is that how the soil deformation might change the void ratio and soil particle preferential orientation. The constant void ratio indicates that the soil particles have no preferred orientation changes. In this case, anisotropic permeability has not changed and the values of $k_{h}$ and $k_{v}$ follow the $k_{h \text { (max) }}$ and $k_{v(\min )}$ curves. However, if the soil shows any void ratio changes, it should be due to the changes in anisotropic permeability that may cause the values of $k_{h}$ and $k_{v}$ not to follow the $k_{h(\max )}$ and $k_{v(\min )}$ curves.
The results show that measured permeability's $\left(k_{h 1}, k_{h 2}\right.$ and $k_{v}$ ) have good coincidence with the $k_{h(\max )}$ and $k_{v(\min )}$ curves that validate the conceptual model. The preparation method of samples affects the $k_{h(\max )}$ and $k_{v(\min )}$ curves at very high void ratios (approximately larger than 1), but at lower void ratios, its effects on these curves are negligible. Both conceptual model and validating tests show that, in any soil deformation, the soil particles orientation or structural anisotropy do not change in a fixed void ratio. So the void ratios have a significant role in the permeability for two reasons in soil deformation; the void ratio changes have a larger effect on the permeability relative to the soil structural anisotropy changes. Also, the soil particles' orientation and anisotropy do not change while the void ratio is relatively constant.

\section{Data Availability}

The data used to support the findings of this study are available from the corresponding author upon request.

\section{Conflicts of Interest}

The authors declare that there are no conflicts of interest regarding the publication of this paper.

\section{Acknowledgments}

The authors thank the valuable advices of Dr. H. Rezaee about the loess soils of Golestan Province. Moreover, the authors also thank Faghani Industrial Factory for their collaboration in building the test apparatus of this study and giving technical advices. The authors also appreciate the support of Golestan Regional Water Company in the sampling process.

\section{References}

[1] S. S. Agus, E. C. Leong, and H. Rahardjo, "A flexible wall permeability for measurements of water and air coefficient of permeability of residual soil," Canadian Geotechnical Journal, vol. 40, no. 3, pp. 559-574, 2011.

[2] G. Cai, A. Zhou, and D. Sheng, "Permeability function for unsaturated soils with different initial densities," Canadian Geotechnical Journal, vol. 51, no. 12, pp. 1456-1467, 2014.

[3] S. Huang, D. G. Fredlund, and S. L. Barbour, "Measurement of the coefficient of permeability for a deformable unsaturated soil using a triaxial permeameter," Canadian Geotechnical Journal, vol. 35, no. 3, pp. 426-432, 1998.

[4] T. R. Green, L. R. Ahuja, and J. G. Benjamin, “Advances and challenges in predicting agricultural management effects on soil hydraulic properties," Geoderma, vol. 116, no. 1-2, pp. 3-27, 2003.

[5] S.-S. Yeo, C. D. Shackelford, and J. C. Evans, "Consolidation and hydraulic conductivity of nine model soil-bentonite backfills," Journal of Geotechnical and Geoenvironmental Engineering, vol. 131, no. 10, pp. 1189-1198, 2005.

[6] S. A. Berilgen, M. M. Berilgen, and I. K. Ozaydin, "Compression and permeability relationships in high water content clays," Applied Clay Science, vol. 31, no. 3-4, pp. 249-261, 2006. 
[7] R.-D. Fan, Y. J. Du, K. R. Reddy, S. Y. Liu, and Y. L. Yang, "Compressibility and hydraulic conductivity of clayey soil mixed with calcium bentonite for slurry wall backfill: initial assessment," Applied Clay Science, vol. 101, pp. 119-127, 2014.

[8] A. Royal, A. W. Opukumo, C. S. Qadr, L. M. Perkins, and M. A. Walenna, "Deformation and compression behavior of a cement-bentonite slurry for groundwater control applications," Geotechnica and Geologica Engineering, vol. 36, no. 2, pp. 835-853, 2018.

[9] W. R. Bryant, W. Hottman, and P. Trabant, "Permeability of unconsolidated and consolidated marine sediments, Gulf of Mexico," Marine Geotechnology, vol. 1, no. 1, pp. 1-14, 1975.

[10] C. A. Morrow, L. Q. Shi, and J. D. Byerlee, "Permeability of fault gouge under confining pressure and shear stress," Journal of Geophysical Research: Solid Earth, vol. 89, no. B5, pp. 3193-3200, 1984.

[11] J. Arch and A. Maltman, "Anisotropic permeability and tortuosity in deformed wet sediments," Journal of Geophysical Research, vol. 95, no. B6, pp. 9035-9045, 1990.

[12] S. Zhang and S. F. Cox, "Enhancement of fluid permeability during shear deformation of a synthetic mud," Journal of Structural Geology, vol. 22, no. 10, pp. 1385-1393, 2000.

[13] B. R. Crawford, D. R. Faulkner, and E. H. Rutter, "Strength, porosity, and permeability development during hydrostatic and shear loading of synthetic quartz-clay fault gouge," Journal of Geophysical Research, vol. 113, no. B3, 2008.

[14] S. Kimura, H. Kaneko, T. Ito, and H. Minagawa, "Investigation of fault permeability in sands with different mineral compositions (evaluation of gas hydrate reservoir)," Energies, vol. 8, no. 7, pp. 7202-7223, 2015.

[15] S. Kimura, H. Kaneko, S. Noda, T. Ito, and H. Minagawa, "Shear-induced permeability reduction and shear-zone development of sand under high vertical stress," Engineering Geology, vol. 238, pp. 86-98, 2018.

[16] A. Al-Tabbaa and D. M. Wood, "Some measurements of the permeability of kaolin," Géotechnique, vol. 37, no. 4, pp. 499-514, 1987.

[17] R. P. Chapuis and D. E. Gill, "Hydraulic anisotropy of homogeneous soils and rocks: influence of the densification process," Bulletin of the International Association of Engineering Geology, vol. 39, no. 1, pp. 75-86, 1989.

[18] D. N. Dewhurst, K. M. Brown, M. B. Clennell, and G. K. Westbrook, "A comparison of the fabric and permeability anisotropy of consolidated and sheared silty clay," Engineering Geology, vol. 42, no. 4, pp. 253-267, 1996.

[19] A. Dhowian and T. Edil, "Consolidation behavior of peats," Geotechnical Testing Journal, vol. 3, no. 3, pp. 105-114, 1980.

[20] S. Leroueil, G. Bouclin, F. Tavenas, L. Bergeron, and P. La Rochelle, "Permeability anisotropy of natural clays as a function of strain," Canadian Geotechnical Journal, vol. 27, no. 5, pp. 568-579, 2011.

[21] E. E. Malinowska and A. Szymański, "Vertical and horizontal permeability measurements in organic soils," Annals of Warsaw University of Life Sciences, Land Reclamation, vol. 47, no. 2, pp. 153-161, 2015.

[22] G. Mesri and R. E. Olson, "Mechanisms controlling the permeability of clays," Clays and Clay Minerals, vol. 19, pp. 151-158, 1971.

[23] H. W. Olsen, "Hydraulic flow through saturated clays," Clays and Clay Minerals, vol. 9, pp. 131-161, 1960.

[24] P. W. Rowe and L. Barden, "A new consolidation cell," Géotechnique, vol. 16, no. 2, pp. 162-170, 1966.
[25] W. B. Wilkinson and E. L. Shipley, "Vertical and horizontal laboratory permeability measurements in clay soils," Developments in Soil Science, vol. 2, pp. 285-298, 1972.

[26] G. Cheng, H.-H. Zhu, Y.-N. Wen, B. Shi, and L. Gao, "Experimental investigation of consolidation properties of nanobentonite mixed clayey soil," Sustainability, vol. 12, no. 2, p. $459,2020$.

[27] R. A. Reid, Triaxial Permeability Device, M. S. Thesis, Georgia Institute of Technology, Atlanta, Georgia, 1988.

[28] W. R. Whalley, G. P. Matthews, and S. Ferraris, "The effect of compaction and shear deformation of saturated soil on hydraulic conductivity," Soil and Tillage Research, vol. 125, pp. 23-29, 2012.

[29] H. Lei, Y. Wu, Y. Yu, and B. Zhang, "Influence of shear on permeability of clayey soil," International Journal of Geomechanics, vol. 16, no. 5, 2016.

[30] G. Wang, W. Wang, and X. Wei, "A ring-shear radial-seepage apparatus for evaluating the permeability of shear bands in compacted clay," Geotechnical Testing Journal, vol. 44, 2020.

[31] S. Zhang, T. E. Tullis, and V. J. Scruggs, "Permeability anisotropy and pressure dependency of permeability in experimentally sheared gouge materials," Journal of Structural Geology, vol. 21, no. 7, pp. 795-806, 1999.

[32] K. M. Brown and J. C. Moore, "Comment on "Anisotropic permeability and tortuosity in deformed wet sediments" by J. Arch and A. Maltman," Journal of Geophysical Research: Solid Earth, vol. 98, no. B10, pp. 17859-17864, 1993.

[33] R. P. Chapuis, "Predicting the saturated hydraulic conductivity of soils: a review," Bulletin of Engineering Geology and the Environment, vol. 71, no. 3, pp. 401-434, 2012.

[34] B. Dolinar, "Predicting the hydraulic conductivity of saturated clays using plasticity-value correlations," Applied Clay Science, vol. 45, no. 1-2, pp. 90-94, 2009.

[35] A. Ilek and J. Kucza, "A laboratory method to determine the hydraulic conductivity of mountain forest soils using undisturbed soil samples," Journal of Hydrology, vol. 519, pp. 1649-1659, 2014.

[36] J. Kucza and A. Ilek, "The effect of the shape parameters of a sample on the hydraulic conductivity," Journal of Hydrology, vol. 534, pp. 230-236, 2016.

[37] M. A. Malusis, C. D. Shackelford, and H. W. Olsen, "Flow and transport through clay membrane barriers," Engineering Geology, vol. 70, no. 3-4, pp. 235-248, 2003.

[38] M. Mejías, P. Renard, and D. Glenz, "Hydraulic testing of lowpermeability formations," Engineering Geology, vol. 107, no. 34, pp. 88-97, 2009.

[39] X. Ren, Y. Zhao, Q. Deng, J. Kang, D. Li, and D. Wang, “A relation of hydraulic conductivity - void ratio for soils based on Kozeny-Carman equation," Engineering Geology, vol. 213, pp. 89-97, 2016.

[40] A. J. Roque and G. Didier, "Calculating hydraulic conductivity of fine-grained soils to leachates using linear expressions," Engineering Geology, vol. 85, no. 1-2, pp. 147-157, 2006.

[41] M. D. Sante, E. Fratalocchi, F. Mazzieri, and V. Brianzoni, "Influence of delayed compaction on the compressibility and hydraulic conductivity of soil-lime mixtures," Engineering Geology, vol. 185, pp. 131-138, 2015.

[42] D. W. Taylor, Fundamentals of Soil Mechanics, John Wiley \& Sons, NY, USA, 1948.

[43] Q. Wang, Y.-J. Cui, A. M. Tang, J.-D. Barnichon, S. Saba, and W.-M. Ye, "Hydraulic conductivity and microstructure changes of compacted bentonite/sand mixture during hydration," Engineering Geology, vol. 164, pp. 67-76, 2013. 
[44] S. Zhang, H. Grip, and L. Lövdahl, "Effect of soil compaction on hydraulic properties of two loess soils in China," Soil and Tillage Research, vol. 90, no. 1-2, pp. 117-125, 2006.

[45] P. C. Carman, Flow of Gases through Porous Media, Butterworths Scientific Publications, London, England, 1956.

[46] R. P. Chapuis, "Predicting the saturated hydraulic conductivity of sand and gravel using effective diameter and void ratio," Canadian Geotechnical Journal, vol. 41, no. 5, pp. 787-795, 2011.

[47] P. Raju, N. S. Pandian, and T. S. Nagaraj, "Analysis and estimation of coefficient of consolidation," Geotechnical Testing Journal, vol. 18, no. 2, pp. 252-258, 1995.

[48] A. M. Samarasinghe, Y. H. Huang, and V. P. Drnevich, "Permeability and consolidation of normally consolidated soils," Geotechnical Engineering Division, ASCE, vol. 108, no. 6, pp. 835-850, 1982.

[49] Q. Liu, Y. Wu, Q. Li, and Y. Yu, "Modified model for hydraulic conductivity of clayey soil under shear," International Journal of Geomechanics, vol. 19, no. 11, 2019.

[50] B. C. O'Kelly, "Compression and consolidation anisotropy of some soft soils," Geotechnical and Geological Engineering, vol. 24, no. 6, pp. 1715-1728, 2006.

[51] O. N. Scholes, S. A. Clayton, A. F. A. Hoadley, and C. Tiu, "Permeability anisotropy due to consolidation of compressible porous media," Transport in Porous Media, vol. 68, no. 3, pp. 365-387, 2007.

[52] P. Basak, "Soil structure and its effects on hydraulic conductivity," Soil Science, vol. 114, no. 6, pp. 417-422, 1972.

[53] P. Delage and G. Lefebvre, "Study of the structure of a sensitive Champlain clay and of its evolution during consolidation," Canadian Geotechnical Journal, vol. 21, no. 1, pp. 21-35, 1984.

[54] R. P. Chapuis, D. E. Gill, and K. Baass, "Laboratory permeability tests on sand: influence of the compaction method on anisotropy," Canadian Geotechnical Journal, vol. 26, no. 4, pp. 614-622, 1989.

[55] H. Cetin, "Soil-particle and pore orientations during consolidation of cohesive soils," Engineering Geology, vol. 73, no. 1-2, pp. 1-11, 2004.

[56] R. L. Sloane and T. R. Kell, "The fabric of mechanically compacted kaolin," Clay and Clay Minerals, vol. 14, pp. 289-296, 1966.

[57] G. Mesri and B. Vardhanabhuti, "Compression of granular materials," Canadian Geotechnical Journal, vol. 46, no. 4, pp. 369-392, 2009.

[58] H. Rezaee, G. Lashkaripour, M. Ghafoori, and N. H. Moghaddas, "Measuring the properties of the microstructure loess in Golestan province," Australian Journal of Basic and Applied Sciences, vol. 6, no. 8, pp. 83-92, 2012.

[59] T. W. Lambe and R. V. Whitman, Soil Mechanics, pp. 281-294, John Wiley \& Sons, NY, USA, 1969.

[60] G. Mesri and A. Rokhsar, "Theory of consolidation for clays," Geotechnical Engineering Division, ASCE, vol. 100, no. 8, pp. 889-904, 1974.

[61] Y. Nishida and S. Nakagawa, "Water permeability and plastic index of soils,", in Proceedings of IASH-UNESCO Symposium Tokyo, no. 89, pp. 573-578, Tokyo, Japan, 1970.

[62] F. Tavenas, P. Jean, P. Leblond, and S. Leroueil, "The permeability of natural soft clays. Part II: permeability characteristics," Canadian Geotechnical Journal, vol. 20, no. 4, pp. 645-660, 2011.

[63] R. N. Yong and B. P. Warkentin, Soil Properties and Behaviour, p. 449, Elsevier Scientific Publishing Company, Amsterdam, Netherlands, 1975.
[64] A. Alaoui, J. Lipiec, and H. H. Gerke, "A review of the changes in the soil pore system due to soil deformation: a hydrodynamic perspective," Soil and Tillage Research, vol. 115-116, pp. 1-15, 2011.

[65] K. Beven and P. Germann, "Macropores and water flow in soils," Water Resources Research, vol. 18, no. 5, pp. 1311-1325, 1982.

[66] J. Jang, G. A. Narsilio, and J. C. Santamarina, "Hydraulic conductivity in spatially varying media-a pore-scale investigation," Geophysical Journal International, vol. 184, no. 3, pp. 1167-1179, 2011.

[67] A. R. Dexter, E. A. Czyż, and O. P. Gaţe, "Soil structure and the saturated hydraulic conductivity of subsoils," Soil and Tillage Research, vol. 79, no. 2, pp. 185-189, 2004.

[68] L. Alakukku, "Persistence of soil compaction due to high axle load traffic. I. Short-term effects on the properties of clay and organic soils," Soil and Tillage Research, vol. 37, no. 4, pp. 211-222, 1996.

[69] S. Assouline, D. Tessier, and J. Tavares-Filho, "Effect of compaction on soil physical and hydraulic properties: experimental results and modeling," Soil Science Society of America Journal, vol. 61, no. 2, pp. 390-398, 1997.

[70] V. Dijck and V. Asch, "Compaction of loamy soils due to tractor traffic in vineyards and orchards and its effect on infiltration in southern France," Soil and Tillage Research, vol. 63 , no. 3-4, pp. 141-153, 2002.

[71] F. J. Griffiths and R. C. Joshi, "Change in pore size distribution owing to secondary consolidation of clays," Canadian Geotechnical Journal, vol. 28, no. 1, pp. 20-24, 2011.

[72] J. Lipiec, M. Hajnos, and R. Świeboda, "Estimating effects of compaction on pore size distribution of soil aggregates by mercury porosimeter," Geoderma, vol. 179-180, pp. 20-27, 2012.

[73] Y.-N. Wei, W. Fan, N. Yu, L.-S. Deng, and T. Wei, "Permeability of loess from the South Jingyang Plateau under different consolidation pressures in terms of the three-dimensional microstructure," Bulletin of Engineering Geology and the Environment, vol. 79, no. 1-2, pp. 4841-4857, 2020.

[74] X. W. Ren and J. C. Santamarina, "The hydraulic conductivity of sediments: a pore size perspective," Engineering Geology, vol. 233, pp. 48-54, 2018.

[75] S. H. Haines, B. A. Van Der Pluijm, M. J. Ikari, D. M. Saffer, and C. Marone, "Clay fabric intensity in natural and artificial fault gouges: implications for brittle fault zone processes and sedimentary basin clay fabric evolution," Journal of Geophysical Research, vol. 114, no. B5, 2009. 